\title{
An Exploration of the Construction of China's Eldercare Service Talent Team from the Expectancy Theory Perspective
}

\author{
Chunyang Du, Ruodong Han, Chuqiao Li \\ School of Government, Beijing Normal University, Beijing, China \\ Email: sunshinedcy@163.com,610309288@qq.com,719923036@qq.com
}

How to cite this paper: Du, C.Y., Han, R.D. and Li, C.Q. (2017) An Exploration of the Construction of China's Eldercare Service Talent Team from the Expectancy Theory Perspective. Open Journal of Business and Management, 5, 501-513. https://doi.org/10.4236/ojbm.2017.53043

Received: June 26, 2017

Accepted: July 17, 2017

Published: July 20, 2017

Copyright (c) 2017 by authors and Scientific Research Publishing Inc. This work is licensed under the Creative Commons Attribution International License (CC BY 4.0).

http://creativecommons.org/licenses/by/4.0/

\begin{abstract}
With the change of population structure, the imbalance between the supply and demand of eldercare services is getting more and more critical. Hence, it is imperative to increase the supply of eldercare service talents and stop the serious loss of eldercare service talents. According to the analysis of China's aging situation and construction of eldercare service talent team, this study spotted a severe aging situation of China and insufficient construction of eldercare service talent team: a small number of eldercare talents, serious contradiction between the supply and demand of eldercare talents, structural imbalance, lacking of professionals, high turnover rate, and short of profession identification, etc. Based on modified expectancy theory, this paper is designed to innovate the mode of cultivating and retaining eldercare service talents by combining personal efforts, personal achievements, institutional rewards and personal demands with factors of opportunities, ability, training and learning, raise the expectations and effect of China's eldercare service talent cultivation, maximize the incentive force, and properly handle talent cultivation and retention issues, so that to establish an eldercare service talent team with sufficient talents, reasonable structure and good quality.
\end{abstract}

\section{Keywords}

Eldercare Service, Talent Team, Incentive Mechanism, Expectancy Theory

\section{Introduction}

According to UNESCO, an aging country or area means the proportion of its elderly people over 60 exceeds $10 \%$ of the total number or the proportion of its elderly people over 65 exceeds $7 \%$ of the total population. In 1999, China's elderly population aged over 60 had more than 126 million, accounting for $10 \%$ of 
the total population. The aged 65 and older were 87.25 million, accounting for $6.9 \%$ of the total population [1]. In 2016, China's population aged 60 and above exceeded 230 million people, accounting for $16.7 \%$ of the total population; 65 years of age and over the population of more than 150 million people, accounting for $10.8 \%$ of the total population [2]. Thus, since China entered the aging society in 1999, the aging of population is accelerating day by day, featuring a large population base, rapid growth, advanced aging, disability, and empty-nested trend. Besides, the mixture of current condition of getting old before rich and family miniaturization makes the eldercare even more complicated [3]. Compared with many other countries, China's aging problem turned up late but ferocious. Figure $1^{1}$ describes the process of aging in different countries in the world, of which the longest time for aging is France, with 115 years; the United States spent 60 years, Japan is shorter, spent 24 years, while China entered the aging society only with 18 years (1981-1999), and the aging is still accelerating. On the one hand, China's average lifespan is increasing; on the other hand, due to China's family planning policy, the growth of young population is lower than the natural growth rate, and China's aging situation became more severe, which has raised a global concern.

By the end of 2015, the number of elderly people over 60 is 222 million in China. This population accounted for $16 \%$ of the total population [4], which marked a $3.38 \%$ increase compared with that of 2000 according to the demographic census of the year. It is estimated that by the end of 2020, the number of China's elderly people over will increase to about 222 million, accounting for about $17.8 \%$ of the total population; the number of advanced aging people will increase to about 2.9 million, the number of elderly people living alone and empty-nest elderly people will increase to about 118 million, and the aged-dependency ratio will increase to about $28 \%$, which all showed that China's eldercare problem is becoming more and more severe [5]. Annual Report of Urban Development of China 2015 predicted that by 2050, the number of China's elderly people will reach 483 million accounting for $34.1 \%$ of the total population, and each day about 30 thousand people will become the elderly people. In 2050, the number of China's elderly people will be larger than the total population of

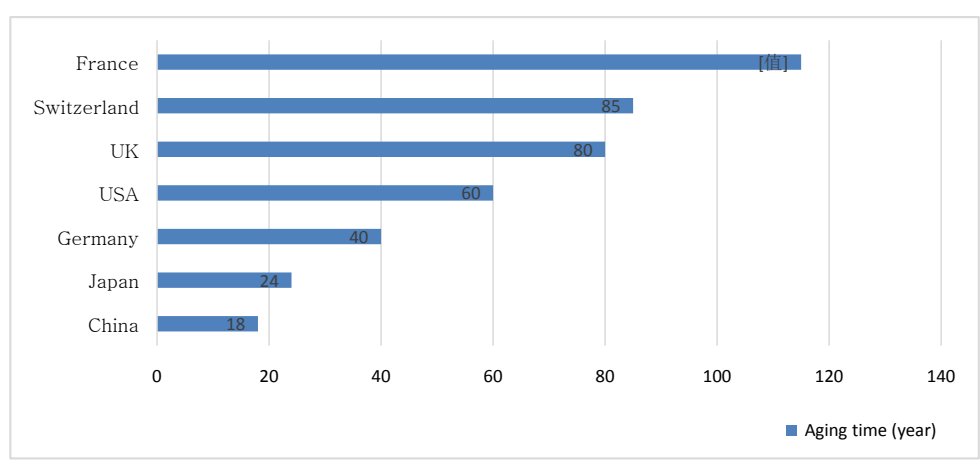

Figure 1. Aging process of some countries.

${ }^{1}$ Source: Consolidated according to the data released by Intelligence Research Center. 
the US, and will account for a quarter of the total population of 2.02 billion of the whole world in 2050 as estimated by the UN. According to the data disclosed by the National Bureau of Statistics of China, this study made a population and proportion trend chart (as shown in Figure $2^{2}$ ) of China's elderly people above 60 based on relevant data of number and proportion of China's elderly people over 60 between 2007 and 2016 as well as the relevant prediction data of 2020 and 2050.

In contrast to the increasing number of elderly people, the number of nursing personnel in China's eldercare institutions is less than 1 million, of which the number of nursing personnel gained professional training and qualifications occupied less than $10 \%$ of the total number of nursing personnel. Moreover, China's empty-nest problem became more prominent, which should not be overlooked. Currently, 54\% of urban aged families are empty-nest families, and almost half of rural aged families became empty-nested in recent years with the increase of migrant laborers.

With the rising of "4-2-1" families (four old people, one couple and one child) and frequent migration of population, traditional eldercare mode is facing unprecedented challenges. Different eldercare forms such as institution eldercare, community eldercare, home-based eldercare and house-for-pension eldercare turned up, which enriched and promoted the development of eldercare. The huge population of elderly people forced a huge demand for eldercare services and eldercare talents. However, problems also appeared one after another, such as whether there is a balance between the supply and demand of current eldercare service talents, whether the services provided by these eldercare talents can satisfy the demands of future eldercare services with the increasing heterogeneity and diversity of eldercare demands, and whether the construction of eldercare service talent team can assure an effective supply of eldercare service talents with high-quality and high-efficiency eldercare series. Based on the discussion of these questions, this paper will analyze the shortage of current construction of eldercare service talent team and innovate the construction of eldercare service talent team on the basis of modified expectancy theory, so that to maximize in-

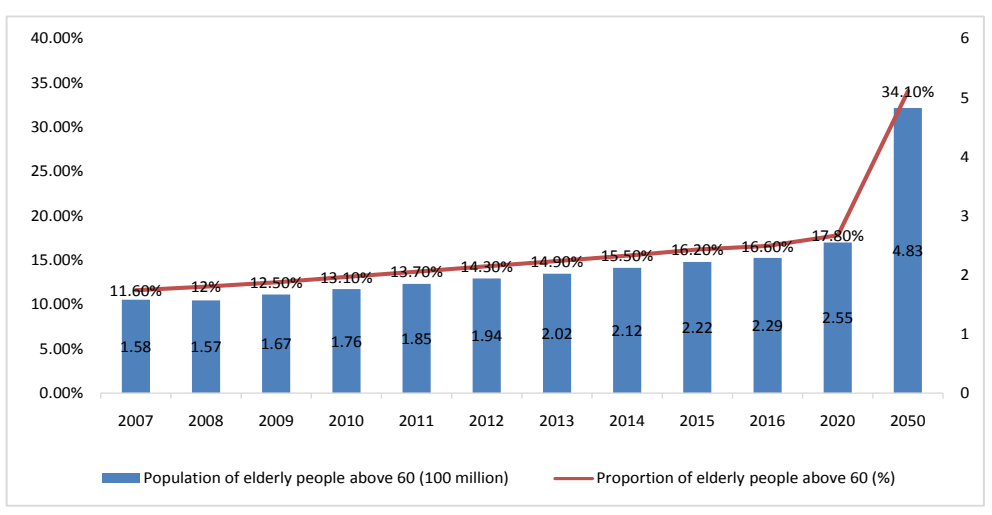

Figure 2. Population and proportion trend chart of China's elderly people above 60 between 2007 and 2050 .

${ }^{2}$ Consolidated according to the data released by the National Bureau of Statistics. 
centive measures and provide powerful talent support in accelerating the construction of eldercare service industry.

\section{Status of Current Construction of Eldercare Service Talent Team}

For the moment, China's eldercare service industry is facing a serious problem in the construction of eldercare service talent team, except for the problems as single industrialized structure, lacking of product diversity, small scale of business, low level of industrialization, and low economic benefit of eldercare industry, etc [6] [7]. Specifically, the realistic difficulties of China's eldercare service talent team construction mainly include small number of eldercare talents, serious contradiction between supply and demand, structural imbalance, lacking of professionals, high turnover rate, and short of occupational identification, etc.

\subsection{Small Number of Eldercare Talents, Serious Contradiction between Supply and Demand}

According to statistics, by 2015, there are over 100 million empty-nesters, 40 million disabled or half-disabled elderly people, and 24 million advanced elderly people in China [8]. According to the internationally recognized standard of one nursing personnel for three disabled old people, Chine requires 13 million nursing personnel. However, the current number of nursing personnel is less than 1 million, and the gap of eldercare nursing talents is conservatively estimated to be more than 10 million [9]. In fact, there are only 700,000 of institution eldercare employees and the proportion of nursing personnel and elderly people settled in eldercare institutions is only 1:7.8 [10], which is far beyond the international standard. The demand for eldercare personnel is even large in Beijing, Shanghai and Guangzhou who became aging cities earlier. However, the professional operation mode of the cultivation mechanism has not been formed for eldercare personnel in China, and the total population of eldercare personnel is quite small, which makes it hard for the supply of eldercare service personnel to satisfy the demand of eldercare institutions.

The investigation on Guangzhou eldercare institutions in Analysis and Forecast on Social Situation of Guangzhou in China (2015) showed that $70 \%$ of the elderly inhabitants of the eldercare institutions cannot take care of themselves or can hardly take care of themselves, and there is a desperate short of nursing personnel in the eldercare institutions. In ten randomly selected eldercare institutions, the total number of nursing personnel is 763 , accounting for $59.2 \%$ of the total employees. Of them, 364 nursing personnel have gained professional nursing certificates, accounting for $47.7 \%$ of the total nursing personnel. The proportion of nursing personnel and elderly inhabitants is 1:7.12. But the proportion should be about 1:5 according to the service standard of eldercare institutions. Obviously, the number of eldercare nursing personnel and professional nursing personnel is lower than the standard, and the supply and demand of the eldercare service talent team is seriously unbalanced. The imbalance will be fur- 
ther aggravated with the increasing number of China's elderly people.

\subsection{Unbalanced Structure and Lack of Professionals}

According to the age distribution of the eldercare service talent team, the eldercare employees are generally old, who are mainly rural migrant laborers, urban "4050" staff (female above 40, male above 50) and re-employed people after retirement. Among the 230, 000 eldercare employees, 130,000 employees are aged from 46 to 65 , accounting for $56.7 \%$ of the total employees; 80,000 employees are post-60s, accounting for $35 \%$ of the total employees; very few young employees such as post-90s can be seen in the group, which accounts only $6.1 \%$ of the total [11]. This shows that a reasonable eldercare service talent team has not been formed. As eldercare services contain certain nursing risks, the eldercare service talent team should absorb more young nursing personnel. Hence, the age structure of the eldercare service talent team needs to be adjusted urgently.

According to the gender distribution of eldercare service talent team, 150,000 are female accounting for $64.12 \%, 80,000$ are male accounting for $35.88 \%$, showing a serious imbalance of gender distribution [11]. Featured with specialty and particularity, eldercare nursing requires more male staff especially for some complicated or special service work. Hence, the gender structure of the eldercare service talent team also needs to be adjusted urgently.

Viewing from the overall level of China's eldercare service talent team, problems as low quality of employees, unreasonable internal structure of talents, and low certified rate still exist [12]. According to statistics, China's eldercare service talent team has a low cultural and skill level. The average percentage of nursing personal with college degree or above is only $15.3 \%$; there is a lack of professionals such as nutritionists, therapists, psychological consultants and social workers. The average percentage of professionals in eldercare personnel is only $9.14 \%$, and the average percentage of social workers in eldercare personnel is only $3.14 \%$ [10]. The overall educational level of the personnel is quite low. Without the guarantee of cultural quality, it is hard for eldercare service personnel to learn new technologies and new knowledge, and improve their occupational level. Hence, the overall level of the eldercare service talent team needs to be enhanced urgently.

Regarding the occupational qualifications of the eldercare service talent team, the certified rate of the nursing personnel in China's eldercare institutions is $57.4 \%$, of which the certified rate of the nursing personnel in social eldercare institutions is only 43.5\% [13]. Most of eldercare service institutions do not have relevant professionals in nursing, legal consultation and psychology. Many nursing employees never attended formal pre-employment training. They learn when work. So the nursing quality is hard to be guaranteed. Hence, the certified proportion of the eldercare service talent team should be also promoted.

Besides, many institutions expressed that recruiting and retaining of employees became more and more difficult. The poor promotion of eldercare service talents also restricted the healthy and sustainable development of the con- 
struction of eldercare service talent team to some extent.

\subsection{High Turnover Rate and Short of Occupational Identification}

According to the salary survey on China's eldercare workers conducted by Social Welfare Center of Ministry of Civil Affairs in 2015, the salary and welfare of the eldercare workers are pretty bad. Most of their salaries are below 3000 RMB per month, and the coverage of their social insurance is also very limited. An investigation by Guangzhou Statistics Bureau of National Bureau of Statistics of China showed that the salaries of the nursing personnel in state-run eldercare institutions ranged from $2000 \mathrm{RMB}$ to $3500 \mathrm{RMB}$ per month; and the salaries of the nursing personnel in private eldercare institutions ranged from $2500 \mathrm{RMB}$ to $5000 \mathrm{RMB}$, according to the operating conditions of the institutions. The investigation on Yuexiu District of Guangzhou showed that the average salary of the nursing personnel of private welfare institutions is about $2800 \mathrm{RMB}$ per month, which is lower than the average level of $3000 \mathrm{RMB}$ per month of Guangzhou. As a result, they have less enthusiasm about their work. Meanwhile, in most of eldercare institutions, one eldercare nursing personnel usually has to take six to seven disabled or half-disabled elderly people. Except for the daily diet and daily life of the elderly people in the daytime, they have to deal with the emergency situation of the elderly people at night. Besides, they only have one day off by turns each week. It is very hard for eldercare institutions to recruit and retain employees. The turnover rate of the workers is also very high. $71.3 \%$ of the employees worked less than five years. Moreover, according to the data provided by the third party and employers, the turnover rate of the graduates in their first year engaged in eldercare industry is $40 \%-50 \%$, the second year is $60 \%-70 \%$, and the third year is $80 \%-90 \%$.

Due to the heavy workload, poor welfare and salary, lacking of occupational identification, and limited promotion space, many nursing personnel cannot focus on their work and job-hopped frequently. On the one hand, the workload of the eldercare nursing personnel is very heavy. They have to work long hours in a monotonous working environment. But they cannot get a reasonable return, which will surely dampen their enthusiasm in their work. On the other hand, most of the nursing personnel who work in high intensity received no specialized technical training. They have low professional skills and communicate insufficiently with the elderly people, which increased the difficulties and stress of the nursing workers. In addition, the workers receive no training and promotion for their professional skills after they take the job. As a result, the workers may not be treated fairly and they will be lack of occupational identification.

A high-quality eldercare service talent team is the guarantee of high-quality eldercare services. However, the construction of China's eldercare service talent team is experiencing a dilemma situation: coexistence of short of eldercare service talents, structural imbalance and serious turnover of nursing workers [14]. Under such a practical background, the research on how to enhance the improvement and development of the construction system of eldercare service tal- 
ent team and establish an effective cultivation mechanism of eldercare service talents is a great challenge and opportunity to China's eldercare career.

\section{Expectancy Theory and Its Application to the Construction of Eldercare Service Talent Team}

\subsection{Overview of Vroom's Expectancy Theory}

Expectancy theory (also known as Valence-Instrumentality-Expectancy Theory) was first proposed by Victor H. Vroom, a well-known American managerial psychologist, in his book Work and Motivation in 1964. As an important component of management process motivation theory, expectancy theory mainly analyzes the essential conditions that maximize the performance of "motivators".

Vroom believes the motivational force of work over an individual depends on the expectancy value of the outcome he can achieve and the expectancy probability of the expected outcome. Hence, the motivation power can be expressed as $\mathrm{M}=\mathrm{E} \times \mathrm{V}$. In this formula, $\mathrm{M}$ stands for the motivational force to achieve the outcome; it is the potential strength generated by motivating individuals' enthusiasm. E refers to expectancy; it is the possibility of achieving the goals based on previous experience, namely, the subjective probability of achieving goals. $\mathrm{V}$ is short for Valence; it is the value an individual places on the rewards of an outcome, which is related to personal needs, goals, subject attitudes, and personal characteristics. For each goal, there can be three different kinds of valence for each individual: negative, zero, and positive. According to the above formula, for each goal, its expectancy is negatively correlated to valence. Goals with great difficulties are of low success probability; but these kinds of goals always indicate important social significance and can well satisfy individuals' sense of achievement, presenting high valence. On the contrary, goals with high success probability are related to low valence. Therefore, it is critical to set rational extrinsic goals during motivational process, which can provide both the hope of success and the motivation for achieving these goals.

Expectancy theory holds that the handling of the following three relationships is very important during motivational process: the relationship between effort and performance; the relationship between performance and reward; the relationship between reward and the satisfaction of individual needs. However, the satisfaction degree varies with employees' conditions, including gender, age, financial circumstance, and social position. For this reason, a motivational measure could have different motivational effects on different employees, which is illustrated in Figure 3.

The model in Figure 3 reflects the accomplishment process of a goal, according to which an individual can eventually accomplish the task satisfying his (or her) personal needs through efforts. In real life, an accomplished task is followed by a new task. Hence, the mode in Fig. 3 will be modified in the following section. Although Vroom's expectancy theory contains certain deficiencies, such as his ignored of personal capability and social opportunity for performance, it well 


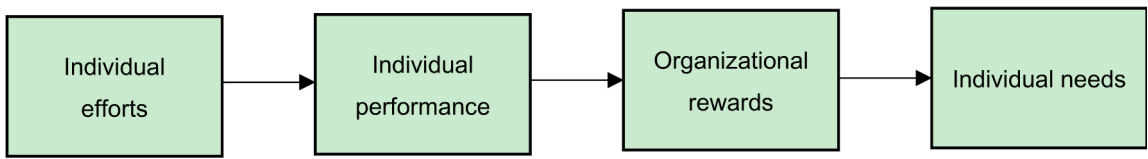

Figure 3. Vroom's expectancy theory.

grasps the key of the problem and reveals the intrinsic necessity. Moreover, the expectancy theory is more reasonable and scientific than other motivational theories. Therefore, it is widely applied to management practice.

\subsection{Application of Expectancy Theory to the Construction of Eldercare Service Talent Team}

\subsubsection{Application Principle of Expectancy Theory in Talent Cultivation for Eldercare Service}

In talent cultivation for eldercare service, expectancy value is the cultivation objects' evaluation of cultivation goals. The motivational force of talent cultivation goals over the cultivation objects relies on the coherence between the cultivated talents and the social requirements on the talent. Valence in talent cultivation for eldercare services is related to the assessment of the cultivation objects to occupational positions and corresponding rewards. In other words, valence is determined by the attraction of the occupational positions and rewards to the cultivation objects; whether they can realize their occupational goals is concerned. In order to improve the enrollment rate, to motive the cultivation objects, and to ensure the supply of professional eldercare talents, the two factors (namely, expectancy and valence) in motivation formula should both be maximized, which requires a joint effort between schools and the society.

\subsubsection{Application Principle of Expectancy Theory in Talent Retention for Eldercare Service}

In talent retention for eldercare service, expectancy value is the cultivation objects' evaluation of retention targets. The motivational force of talent retention targets over professional eldercare talents relies on the coherence between the talents' requirements for occupational career development and the retained job positions provided by eldercare organizations. Valence in talent retention for eldercare service is the eldercare talents' evaluation of the retained job positions and the corresponding rewards. In this case, valence is determined by the attraction of the retained job positions and rewards to eldercare talents; whether they can realize their occupational goals is highly concerned. A series of fair and just policies on occupational promotion should be established to motivate talents retention, to ensure the supply of eldercare talents, and to reduce turnover of talents.

\subsection{The Innovation of China's Construction of Eldercare Service Talent Team Based on Expectancy Theory}

\subsubsection{The Application Model of the Innovation of Construction of Eldercare Service Talent Team Based on Expectancy Theory}

The motivational effects are influenced by many factors in real life, including the 
continuity of the work task, work capability, and opportunity. Therefore, the model of eldercare service talent construction can be innovated based the above Vroom's motivational model (see Figure 4).

\subsubsection{Modified Expectancy Theory Model for the Innovation of Eldercare Service Talent Cultivation}

At present, the construction of eldercare service talents in China mainly consists of three levels: vocational education provided by middle and higher vocational colleges to train first-line technician service personnel and managers; degree education provided by colleges and universities to cultivate professional teaching staff and research personnel; vocational training organized by civil ministration departments, eldercare institutions, and social eldercare-related enterprises to cultivate professional personnel. According to the modified expectancy theory and the current eldercare service talent cultivation system in China, a novel eldercare service talent cultivation mode can be established (see Figure 5).

According to the above application principle of expectancy theory in eldercare service talent cultivation, the training objects tend to invest more efforts if the training processes are highly consistent with social requirements for talents; in this case, the expectancy value can exert strong motivational force on students. If the job positions and rewards can hold strong attraction for the training objects, it will be easier for them to realize their occupational goals, indicating high valence to the training objects. Besides, the heterogenization and diversification of eldercare demands are now urging that the cultivation of eldercare service talents should make progress with the times and provide training objects more opportunities for practice, thus improving the consistency of cultivation goals to social requirements. Therefore, the eldercare service-related curriculums in colleges should involve multiple realms and focus on both theoretical research and basic professional courses. It is also important to enhance the applicability and practicability of the course contents. Hence, the cultivation objects are required

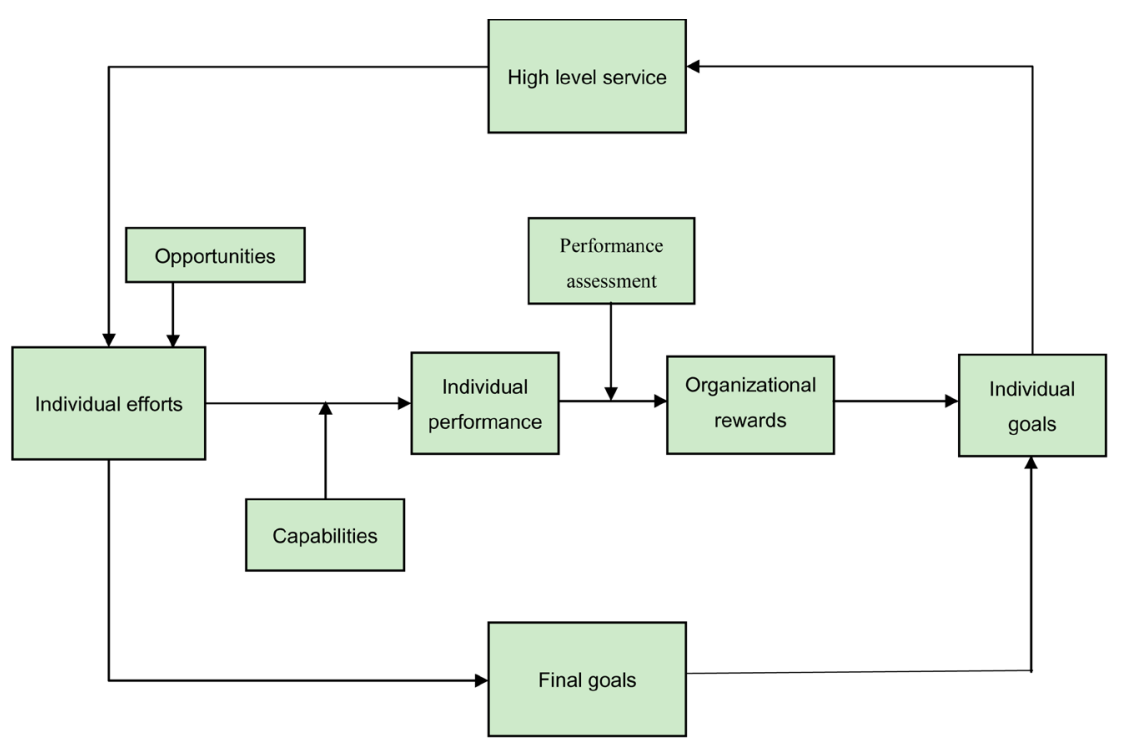

Figure 4. The modified expectancy theory model. 


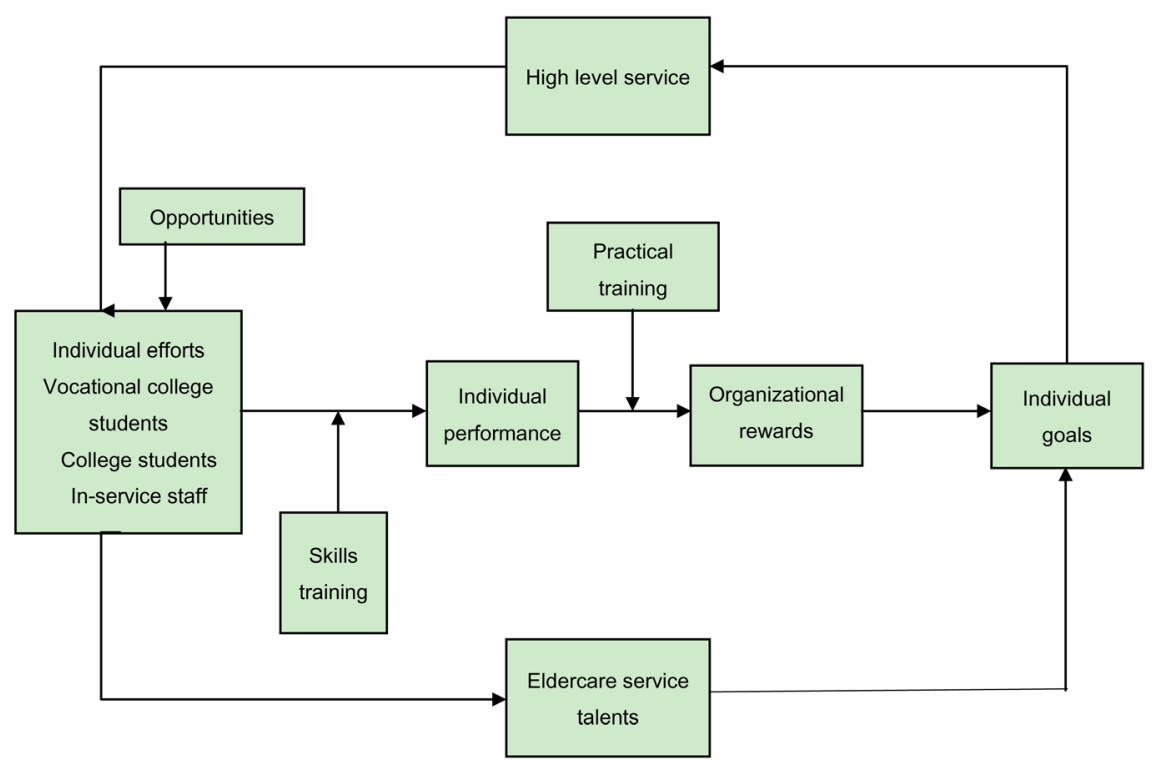

Figure 5. Eldercare service talent cultivation mode based on modified expectancy theory.

to master basic professional skills and acquire related theoretical knowledge, such as geriatric psychology, nursing, and physiology. The teaching mode of Japanese "nursing care for the elderly" can be introduced to Chinese colleges and universities, enabling students to have a good mastery of both theoretical knowledge and practical skills through the combination of CD presentation with textbook contents. Colleges should also try to cooperate with eldercare-related organizations, which can offer students more chances of practical training, thus achieving "the integration of work and study".

\subsubsection{Modified Expectancy Theory Model for the Innovation of Retaining Eldercare Service Talents}

The high turnover of talents is also an important cause of serious imbalance between the supply and demand of eldercare service talents construction in China. How to improve eldercare service talents' occupational self-identity and to increase retention rate is an important issue demanding urgent solutions. Based on the modified expectancy theory and the current eldercare service talent cultivation system in China, a novel eldercare service talent retention mode can be created (see Figure 6).

Based on the application principle of expectancy theory in eldercare service talent cultivation, in the case of eldercare service talents retention, the motivational force of expectancy value over students will increase if the retained positions satisfy the talents' occupational development needs. If the retained job positions and rewards hold strong attraction for eldercare talents, it will be easier for them to realize their occupational goals, thus bringing in high valence to the training objects. In order to reduce staff turnover, to motivate professional nursing personnel, and to ensure the supply of professional eldercare talents, the government should accelerate the construction of reasonable evaluation system and incentive mechanism for professional eldercare service talents. Scientific 


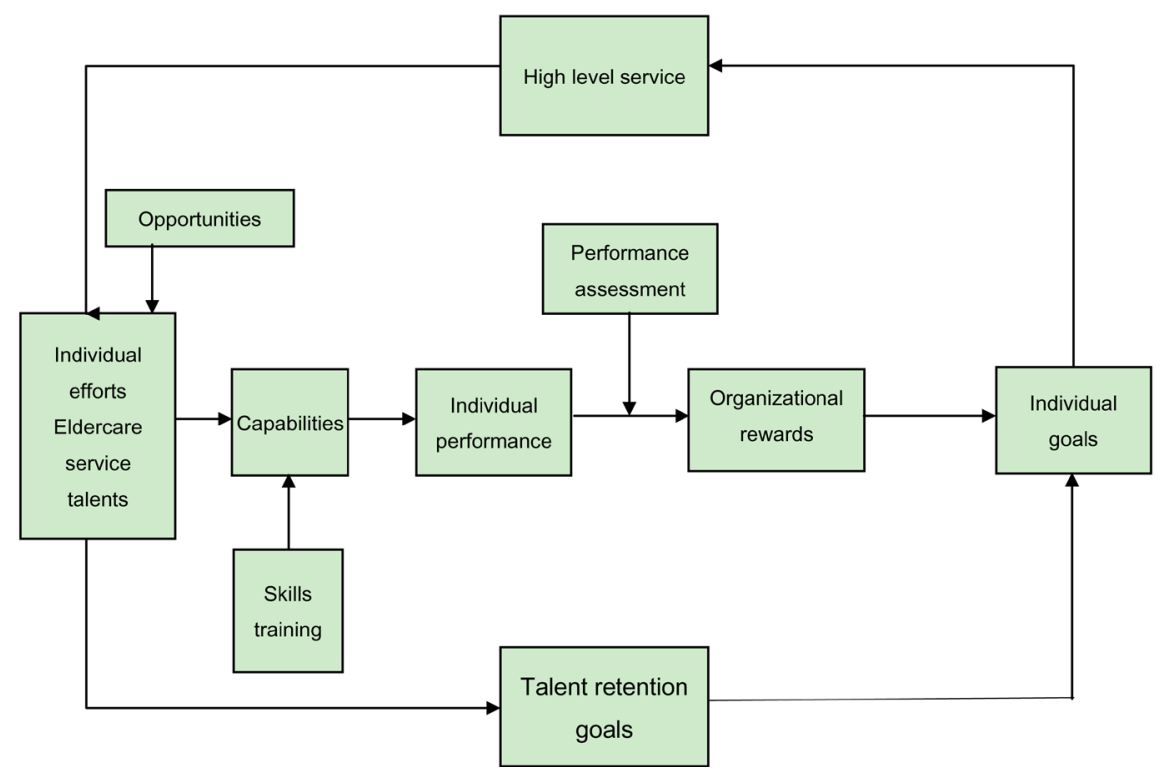

Figure 6. Eldercare service talent retention mode based on modified expectancy theory.

talent evaluation standards should also be established. Eldercare service talents' occupational capabilities should be combined with educational background, working contents, occupational admittance standards, and the evaluation standards of professional skills. Meanwhile, the government should provide practitioners wider space and more opportunities for occupational development and promotion, encouraging eldercare workers to take an active part in new realms (e.g. psychological consultation and health care) to improve their professional skills. In addition, the incentive mechanism should be improved, offering professional eldercare service personnel with subsidies for their tuition, salary, travel, and living expenses. The salary system should also be modified to perfect the social protection system in accordance with professional talents' task, position, and performance-based payment. The government should increase provision of humanistic care for eldercare service personnel, try to enrich their spiritual life and care for their mental health, and provide support and assistance when necessary.

\section{Conclusion}

China's aging is featured with a trend of rapid in growth, advanced aging and getting old before rich. However, the construction of eldercare service talents in China is now facing serious contradictions between the supply and demand for professional eldercare talents, while the total number of eldercare personnel is very low. Besides, there is an imbalance of structure and a lack of professional talents. Furthermore, the turnover of eldercare staff is very high, and the people lack occupational self-identity. High-quality eldercare service talents are guarantee of superior eldercare service. How to turn these challenges into opportunities is the key to China's construction of eldercare service talent team. The academic significance of the study is based on the actual enrichment and develop- 
ment expectation theory. The social significance of the study is that it has some guiding significance in combining with the construction of the service base of the Chinese eldercare service talents construction, improving the expectation theory and applying it to the construction of t Chinese eldercare service talents.

This research is conducted based on the actual situation of Chinese eldercare service talent team construction by modifying expectancy theory and applying it to the construction of eldercare service talents. As regards the cultivation of eldercare service talents, the organizations should enhance the enrollment strength, improve talents output, and cultivate qualified eldercare service talents at all levels. Based on the cultivation mode for eldercare service talents based on modified expectancy theory, training organizations should focus on both theoretical research and basic professional courses, pay attention to the practicability and applicability of the curriculum contents, provide trainees more internship opportunities, and cultivate qualified eldercare service talents satisfying social demands. Furthermore, the organizations should also enhance the attraction of job positions and rewards for the cultivation objects, thus maximizing the motivational effects. When it comes to eldercare service talent retention, the key is to improve eldercare talents' occupational self-identity and to enhance talents retention rate. According to the eldercare service talents retention mode based on modified expectancy theory, the government should accelerate the construction of evaluation system and incentive mechanism for professional eldercare service talents. The training incentive mechanism, salary system, and social protection system should all be improved. Meanwhile, the government should provide practitioners wider space and more opportunities for occupational development and promotion. The eldercare service talent cultivation and retention mode based on modified expectancy theory can be used to guide the planners of eldercare service talent team construction. Individual efforts, performance, organizational rewards, and individual needs should be combined with opportunities, capacities, and trainings. This circular dynamic mode can maximize the motivational force and solve the talent cultivation and retention problem, thus providing solid talents support for the acceleration of eldercare service industry construction.

\section{References}

[1] (2000) China Aging Association Research Report 1999 China Report on Aging. China Social Welfare and Social Progress Report. Social Science Literature Publishing House, 169-188.

[2] Statistical Communiqué of the People's Republic of China on National Economic and Social Development in 2016. National Bureau of Statistics. http://www.stats.gov.cn/tjsj/zxfb/201702/t20170228_1467424.html

[3] Cheng, X. (2013) Research on the Construction of Chongqing Eldercare Service Talent Team. Chongqing University, Chongqing.

[4] Social Service Development Statistical Bulletin of 2015. Web Portals of Civil Administration Department. http://www.mca.gov.cn/article/sj/tigb/201607/20160700001136.shtml 
[5] The Notice about the 13th Five-Year Plan for the Development of Aging Cause and Construction of Eldercare System Published by the State Council. The Chinese Government Website. http://www.cncaprc.gov.cn/contents/2/179240.html

[6] Liu, Y. (2015) The Situation, Problems, and Solutions to the Development of China's Eldercare Service Industry. The Science Education Article Collects, 7, 187-188.

[7] Zhu, H.T. (2014) The Shortage of Eldercare Talents: New Challenge of Aging Society. Chinese Talents, 7, 32-33.

[8] Wu, Y.S., Wang, L.L., Kong, W., Dong, P.T. and Yang, X.Q. (2015) Research on the Development of Chinese Eldercare Organizations. Scientific Research on Aging, 8 , 13-24.

[9] Wang, X.H. (2015) The Research Review of Chinese Eldercare Service Team Construction. Scientific Research on Aging, 11, 41-50.

[10] Zhang, X.F. (2015) The Four Problems of Eldercare Service Team Construction Requiring Urgent Solutions. Social Welfare, 12, 48.

[11] Zheng, X.Y. (2017) Research on Eldercare Service Practitioners' Occupational Delimma and Incentive Measures. Silk Roads, 4, 79-80.

[12] Li, J., Xu, G.H., Jiang, R.R. and Jiang, G.X. (2012) Current Situation and Talent Cultivation Prospect of Chinese Eldercare Service Personnel. Journal of Nanjing University of Traditional Chinese Medicine (Social Science Version), 4, 236-239.

[13] Yang, X.K. (2011) Remedy the Service "Shortcomings" for "Guarantee of Eldercare for the Elderly". Guizhou Daily.

[14] Liu, L.J. (2012) Strategy Research on Eldercare Service Professional Talent Team Construction. Social Welfare (Theoretical Version), 4, 34-39.

\section{Scientific Research Publishing}

\section{Submit or recommend next manuscript to SCIRP and we will provide best} service for you:

Accepting pre-submission inquiries through Email, Facebook, LinkedIn, Twitter, etc. A wide selection of journals (inclusive of 9 subjects, more than 200 journals)

Providing 24-hour high-quality service

User-friendly online submission system

Fair and swift peer-review system

Efficient typesetting and proofreading procedure

Display of the result of downloads and visits, as well as the number of cited articles

Maximum dissemination of your research work

Submit your manuscript at: http://papersubmission.scirp.org/

Or contact ojbm@scirp.org 